\title{
Elderly male patient with gastrocolic fistula following severe acute necrotising pancreatitis
}

\author{
Dhilip Andrew 자, ${ }^{1}$ Karthik Shyam 다, ${ }^{1}$ Jovis Johny, ${ }^{1}$ Sadhana Beaty ${ }^{2}$
}

${ }^{1}$ Radiology, St John's Medical College Hospital, Bangalore, Karnataka, India

${ }^{2}$ Radio Diagnosis, St John's Medical College Hospital, Bangalore, Karnataka, India

\section{Correspondence to Dr Karthik Shyam; dr.karthikshyam@gmail.com}

Accepted 2 December 2020

Check for updates

(c) BMJ Publishing Group Limited 2021. No commercial re-use. See rights and permissions. Published by BMJ.

\begin{tabular}{l}
\hline To cite: Andrew D, Shyam K, \\
Johny J, et al. BMJ Case \\
Rep 2021;14:e240426. \\
doi:10.1136/bcr-2020- \\
240426
\end{tabular}

\section{DESCRIPTION}

A 60-year-old male patient presented to the Emergency Room (ER) with a history of diarrhoea with abdominal pain for 2 weeks and weight loss of $3 \mathrm{~kg}$ over 1 month, the patient had a history of necrotising pancreatitis a month ago. On examination, patient was afebrile with tachycardia, tachypnoea, low blood pressure and pallor. He had mild tenderness in the epigastric region and rest of systemic examination were within normal limits. His preliminary blood investigation revealed haemoglobin level of 70 $\mathrm{g} / \mathrm{L}$ with normal total count, serum amylase, serum lipase, liver function test and renal function test.

The patient underwent contrast-enhanced CT of the abdomen with oral and intravenous contrast agents. Plain CT images (figure 1A,B) demonstrated mild inflammatory changes in the perigastric and paripancreatic regions with possible fistulous communication between the body of stomach and transverse colon. Gastrografin was given orally before intravenously to demonstrate the fistula in post-contrast study. Post-contrast study (figure 1C,F) outlined the fistulous tract and demonstrated transit of oral contrast agent directed into splenic flexure and descending colon directly. Images of previous contrast-enhanced CT performed a month ago were reviewed, the images (figure 2A-F) demonstrated severe necrotising pancreatitis with necrotic and inflammatory changes in peripancreatic region including the walls of the body of stomach.

One of the commonly reported complication of severe acute pancreatitis and infected pancreatic/peripancreatic necrosis is fistula formation. ${ }^{12}$ Fistula formation can occur anywhere in the gastrointestinal tract, colon followed by duodenum are the two most common sites. ${ }^{3}$ In a gastrocolic fistula (GCF), communication usually occurs between the distal transverse colon and greater curvature of stomach. ${ }^{4}$ The most common cause of GCF are colonic and gastric malignancies while GCF can also occur in peptic ulcer disease, inflammatory bowel disease, diverticular disease, chronic pancreatitis and pancreatic abscess. ${ }^{5}$ GCF due to severe acute pancreatitis is not commonly reported ${ }^{6}$ possible causes for its formation in cases of pancreatitis are (1) direct erosion of adjacent gastrointestinal tract by pancreatic enzymes, (2) intestinal necrosis due to vascular thrombosis and (3) following surgical intervention. ${ }^{3} 7$ Patients with GCF can present

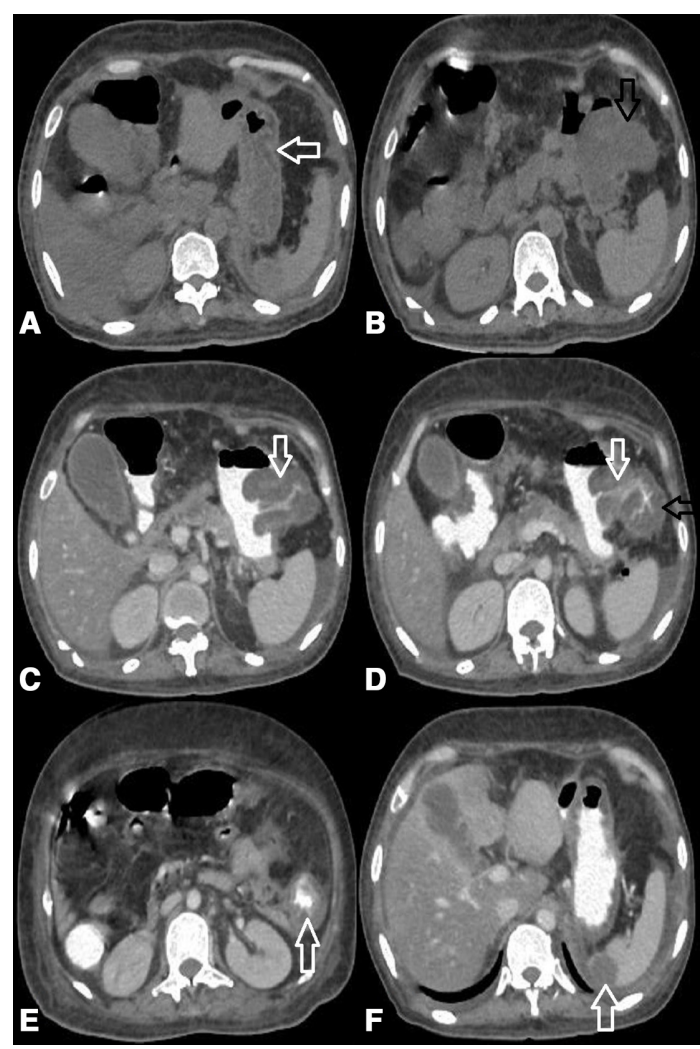

Figure 1 (A) Images of contrast-enhanced CT performed during current admission, (A) pre-contrast image demonstrating gastric wall oedema (white arrow). (B) Pre-contrast image demonstrating suspected tract between stomach and colon (black arrow). (C, D) Postcontrast images demonstrating tract (white arrow) outlined by positive oral contrast between the greater curvature of stomach and transverse colon (black arrow). (E) Post-contrast image demonstrating oral contrast within the descending colon (white arrow). (F) Postcontrast image demonstrating pseudocyst in perisplenic region (white arrow).

with triad of weight loss, vomiting (feculent) and diarrhoea. ${ }^{8} 9$ Other symptoms include fatigue, nutritional deficiencies, abdominal pain and feculent eructations. ${ }^{4}$

Barium enema can be used to evaluate the fistula, ${ }^{5} \mathrm{CT}$ with oral and intravenous contrast is useful in delineating the fistulous tract for preoperative assessment and indentify the underlying aetiology. ${ }^{4810}$ Endoscopy can help to visualise the fistulous tract and take biopsy; however, small and narrow fistulous tracts can be missed. ${ }^{511}$ GCF can lead to complications like malnutrition, sepsis and gastrointenstinal haemorrhage. ${ }^{4}$ 


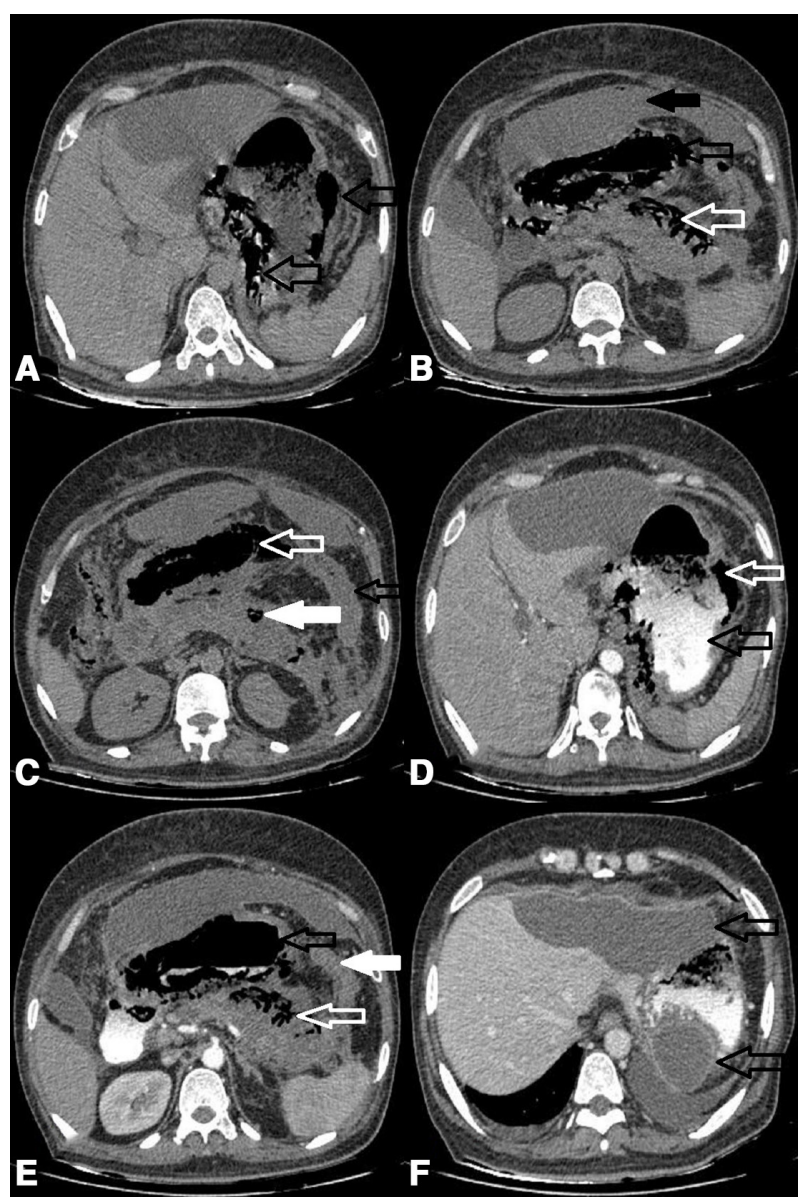

Figure 2 (A) Images of contrast-enhanced CT performed 2 months ago, $(A, B)$ pre-contrast $C T$ images demonstrating multiple air foci within the gastric emphysema (black arrows) and necrotic peripancreatic collection (white arrow). (C) Pre-contrast image demonstrating inflamed pancreas (solid white arrow), normal colon (black arrow) and gastric emphysema (white arrow). (D) Post-contrast image demonstrating gastric emphysema (white arrow) with positive oral contrast in stomach (black arrow). (E) Post-contrast image demonstrating necrotic peripancreatic collection (white arrow) and gastric emphysema (black arrow) and no oral contrast in the colon (white solid arrow). (F) Postcontrast image demonstrating pseudocysts in the perihepatic and perisplenic region (black arrows). Presence of an underlying gastric or colonic fistula couldn't be ruled out since neutral oral contrast was used for the study.

Surgery remains the mainstay treatment. ${ }^{5} 12$ Resection of the fistulous tract with wedge resection of stomach and partial resection of colon is usually performed. ${ }^{13} 14$ Diversion colostomy with excision of the fistulous tract is reserved for debilitated patient. GCF presenting with gastrointestinal haemorrhage requires prompt intervention. ${ }^{5712} \mathrm{GCF}$ closure via over-the-scope clip system, human fibrin sealant and endoscopic closure has been tried with success. ${ }^{14} 15$ Colonic fistulas are associated with increased mortality, ${ }^{3}$ hence prompt diagnosis and treatment is required to prevent complications.

\section{Learning points}

- Gastrocolic fistula can present with a triad of symptoms including vomiting, diarrhoea and weight loss. Vomiting could be feculent associated with feculent eructations.

- Most common cause for gastrocolic fistula are colonic and gastric malignancies. Benign conditions like peptic ulcer disease, diverticular disease, recurrent pancreatitis and pancreatic abscess can lead to fistula formation.

- Gastrocolic fistula can be evaluated by barium enema and contrast-enhanced CT scan. CT scan with water-soluble oral contrast and intravenous contrast can delineate the fistulous tract well.

- Endoscopy can help to locate the tract, but small and narrow tracts can be missed.

Contributors DA, KS, JJ and SB have contributed equally for the article. DA had drafted and reviewed the article, KS and JJ had reviewed and edited the article and SB had reviewed the images and the article.

Funding The authors have not declared a specific grant for this research from any funding agency in the public, commercial or not-for-profit sectors.

Competing interests None declared.

Patient consent for publication Obtained.

Provenance and peer review Not commissioned; externally peer reviewed.

\section{ORCID iDs}

Dhilip Andrew http://orcid.org/0000-0002-6154-3063

Karthik Shyam http://orcid.org/0000-0003-0998-9604

\section{REFERENCES}

1 Kochhar R, Jain K, Gupta V, et al. Fistulization in the Gl tract in acute pancreatitis. Gastrointest Endosc 2012;75:436-40

2 Pandol SJ, Saluja AK, Imrie CW, et al. Acute pancreatitis: bench to the bedside. Gastroenterology 2007;132:1127-51.

3 Jiang W, Tong Z, Yang D, et al. Gastrointestinal fistulas in acute pancreatitis with infected pancreatic or peripancreatic necrosis: a 4-year single-center experience. Medicine 2016:95:e3318.

4 Forshaw MJ, Dastur JK, Murali K, et al. Long-term survival from gastrocolic fistula secondary to adenocarcinoma of the transverse colon. World J Surg Oncol 2005;3:9.

5 Stamatakos M, Karaiskos I, Pateras I, et al. Gastrocolic fistulae; from Haller till nowadays. Int J Surg 2012;10:129-33.

6 Warshaw AL, Moncure AC, Rattner DW. Gastrocutaneous fistulas associated with pancreatic abscesses. An aggressive entity. Ann Surg 1989;210:603-7.

7 Mohamed SR, Siriwardena AK. Understanding the colonic complications of pancreatitis. Pancreatology 2008;8:153-8.

8 Matsuo S, Eto T, Ohara 0, et al. Gastrocolic fistula originating from transverse colon cancer: report of a case and review of the Japanese literature. Surg Today 1994:24:1085-9.

9 Singh V, Wadleigh R. Gastrocolic fistula as a complication of colon carcinoma--a case report. Acta Oncol 1997:36:817-8.

10 Aslam F, El-Saiety N, Samee A. Gastrocolic fistula, a rare complication. BJR|case reports 2018:4:20170121.

11 Kumar GK, Razzaque MA, Naidu VG, et al. Gastrocolic fistulae in benign peptic ulcer disease. Ann Surg 1976;184:236-40.

12 Yin J, Zheng Z, Cai J, et al. Current diagnosis and management of malignant gastrocolic fistulas: a single surgical unit's experience. Int J Clin Exp Med 2014:7:4123-30

13 Ruffolo C, Angriman I, Scarpa M, et al. A gastrocolic fistula in Crohn's disease. Dig Dis Sci 2005:50:933-4.

14 Forbes N, Al-Dabbagh R, Lovrics P, et al. Gastrocolic fistula: a shortcut through the gut. Can J Gastroenterol Hepatol 2016:2016:1-3.

15 Hong T-C, Wu M-S, Liou J-M. A rare case of gastrocolic fistula caused by benign gastric ulcer. Adv Dig Med 2018;5:142-4. 
Copyright 2020 BMJ Publishing Group. All rights reserved. For permission to reuse any of this content visit https://www.bmj.com/company/products-services/rights-and-licensing/permissions/

BMJ Case Report Fellows may re-use this article for personal use and teaching without any further permission.

Become a Fellow of BMJ Case Reports today and you can:

- Submit as many cases as you like

- Enjoy fast sympathetic peer review and rapid publication of accepted articles

Access all the published articles

Re-use any of the published material for personal use and teaching without further permission

Customer Service

If you have any further queries about your subscription, please contact our customer services team on +44 (0) 2071111105 or via email at support@bmj.com.

Visit casereports.bmj.com for more articles like this and to become a Fellow 